\title{
Improve the Photovoltaic Performance of Solar Cells with New Coating Processes
}

\author{
Edward Han
}

\author{
New York university, Apt.1210-A, Gramercy Green, 310 3rd Avenue, New York, NY 10010 \\ edwardhan1115@gmail.com
}

\begin{abstract}
Photovoltaic conversion is a new type of energy generation system that uses the photovoltaic effect of solar cell semiconductor materials to directly convert solar photovoltaics into electrical energy. The purpose of this article is to study the use of new coating technology to improve the photovoltaic performance of solar cells. First of all, the research on the optical characteristics of solar cells is mainly divided into the following two aspects: the use of the concept of new coating technology to influence the photovoltaic performance of $\mathrm{Cu} 2 \mathrm{ZnSnS} 4$ thin films and solar cells, and guide the design of battery active layer materials from the optical aspect; Explain the experimental results from the angle of view, and then improve the photovoltaic performance of solar cells. The experimental results show that when the heating rate is $62^{\circ} \mathrm{C} / \mathrm{min}$, the selenization temperature is $550^{\circ} \mathrm{C}$, the photoelectric performance of the CZTSSe thin film is the best. This article has certain significance and value for studying the choice of new coating technology for solar cells.
\end{abstract}

Keywords: New Coating, Coating Process, Solar Cell, Photovoltaic Performance

\section{INTRODUCTION}

Solar energy has become one of the most promising new energy sources, with many advantages such as independent power generation and grid-connected power generation [1]. The light loss is mainly related to the surface reflection, occlusion and the characteristics of the battery device itself [2]. The cause of electrical loss includes carrier loss and ohmic loss. By using different materials and coating processes, the photovoltaic effect can be extended to higher dimensions, such as polymer solar cells, dye-sensitized solar cells, thin-film solar cells, etc. [3-4].

In order to improve the efficiency of the coating process, researchers have proposed their own schemes from different angles [5]. Lei S L uses a simple citric acid-assisted sol-gel combustion method to synthesize cobalt chromite (CoCr2O4) ceramic pigments. Through thermogravimetric analysis, differential thermal analysis, X-ray diffraction (XRD) and field emission scanning electron microscopy (FESEM), the effect of annealing temperature on the structure, morphology and optical properties of the prepared $\mathrm{CoCr} 2 \mathrm{O} 4$ pigment was systematically studied. The measured solar absorption rate indicates that this ceramic pigment is expected to be used in the production of color paint coatings for solar absorber applications [6]. Some scholars use a mixture of titanium oxide and black mold as a primer, and find out the performance of $20 \%$ by weight and $40 \%$ by weight of solar distiller in the combination of titanium oxide material and black mold. In order to check the effect of water depth on productivity, take readings at different water depths (such as $10 \mathrm{~mm}, 15 \mathrm{~mm}, 20 \mathrm{~mm}$ ). Under the same environmental conditions, the readings of these experiments were compared with a traditional solar distiller (CSS) in the same location (Gandhi Nagar, India, $\left.23.2156^{\circ} \mathrm{N}, 72.6369^{\circ} \mathrm{E}\right)$. The productivity of the mixture of $20 \%$ and $40 \%$ is increased by $11-18 \%$ and $20-23 \%$ [7]. The use of new coating technology to improve the photovoltaic performance of solar cells has certain practical significance.

The research content of this paper deepens the understanding of the choice of solar cell coatings, and provides an effective method for designing and optimizing the experimental program. Research on the selection of coating raw materials, the ratio of raw materials and the thickness of the anti-reflection film is worth learning. At the same time, this article considers the combination of coating technology and photovoltaic performance for the first time, which points out the direction for how to choose materials to prepare solar 
cell coatings. Designing a stable coating process can produce a large-area coating process with stable performance and low preparation cost, which can be applied to the field of solar energy and promote the development of solar thermal technology in China.

\section{RESEARCH ON IMPROVING THE PHOTOVOLTAIC PERFORMANCE OF SOLAR CELLS BY USING NEW COATING TECHNOLOGY}

\subsection{Solar Cell}

Pollutants generated during the production of monocrystalline silicon solar energy are not conducive to environmental protection [8-9]. Although the cost of manufacturing polycrystalline silicon solar cells is lower than that of monocrystalline silicon solar cells, they dominate the solar cell industry due to their similarity to monocrystalline silicon solar cells. Compared with stone-mineral batteries, amorphous silicon solar cells can be decomposed through the application and processing of bottled mineral batteries [10-11], thus having a certain price competitive advantage.

Quantum dot solar cells are a type of solar cells that use semiconductor nanocrystalline materials as narrow band gap light-absorbing materials to adjust the light-absorbing range. Quantum dot sensitizers have the advantages of good chemical stability, low synthesis cost and high extinction. Commonly used semiconductor materials such as $\mathrm{CdS}, \mathrm{PbS}, \mathrm{SnS}, \mathrm{ZnO}$, InP, etc. [12]. It's just that quantum dot solar cells are still in the research stage, and they are far from reaching the maximum theoretical efficiency of $44 \%$. The main working principle of dye-sensitized solar cells is that the photosensitizer absorbs light to excite electron-hole pairs, the electrons are collected by the photoanode (such as $\mathrm{TiO} 2$ ), and the sensitizer in the oxidation state is reduced by the redox electrolyte. The production process is simple and the equipment is cheaper, so the cost performance is higher than that of monocrystalline silicon solar cells.

\subsection{Coating Process}

(1) Semiconductor coating

There are always gaps in semiconductors. If the incident photon power is greater than the semiconductor power gap, the incident photon will be absorbed and the valence electrons will switch to control. Since the energy of the incident photon is smaller than the energy gap of the semiconductor, it can penetrate directly without being affected. Therefore, the coating can be provided by selecting a semiconductor material with a good power gap (preferably $0.62 \mathrm{eV}$ ).

(2) Multilayer interference filter coating
The optical characteristics of the wavelength of light are determined by the self-interference optical effect of the illuminating light in the field of view of each layered system and the specially designed light. This type of coating is a very thin medium metal film system.

\section{(3) Slightly uneven surface coating}

The sun absorbing surface can also be prepared by providing a more uniform surface and better surface texture on the surface of a high-infrared metal substrate. The shallow surface has different effects on long-wave and short-wave radiation. In the case of short-wave generation, due to the rough surface, the incident light is completely absorbed by multiple reflections and absorptions at the micro-holes. In the case of long-wave radiation, it acts like a mirror and reflects it, resulting in lower surface radiation.

\subsection{Preparation Method of Coating}

(1) Vacuum evaporation method

The vacuum evaporation method refers to the heat generated by the material contained in the container. Since this material is non-thin film, it requires a lower compression rate in a warmer environment. When the temperature rises, the raw materials and internal molecules escape. When these escaped molecules or particles meet the sinking bottom during operation, they enter the vacuum chamber and are stored on the top as a thin layer.

(2) Chemical vapor deposition method

CVD is also called a chemical reaction process. The coating material is made in the form of metal or other alloy compounds. Generally, contact with the surface of the substrate under high-temperature cooling or protective gas such as argon or hydrogen, causing chemical reactions such as decomposition, fracture, and replacement, and finally deposited on the surface of the substrate to form a coating.

(3) Electrochemical conversion method

First, attach the necessary metal plate to the positive electrode of the DC power supply, and put it into the phosphoric acid electrode for electrolysis. Next, the metal plate is inserted into the electrolyte containing the salted metal, and the metal particles are electrolyzed into small holes to form a plating method called electrochemical conversion method.

\section{INVESTIGATION AND RESEARCH ON IMPROVING THE PHOTOVOLTAIC PERFORMANCE OF SOLAR CELLS BY NEW COATING PROCESS}

\subsection{Experimental Method}

In order to make the power generation coatings more 
widely used, the entire solar cell is prepared in the form of wallpaper, so that it can be applied on any building surface. Using coated paper as a carrier, a conductive paint is first coated on it as a conductive primer and the counter electrode part of the solar cell, and then a quasi-solid electrolyte and solar power coating are coated to prepare functional paper, thereby preparing solar cell wallpaper. The X-ray energy spectrometer (EDS) of GENESIS manufactured by EDAX in the United States was used to analyze the chemical composition elements of the coating.

\subsection{Preparation of Cu2ZnSnS4 Nanoparticles}

Add $\quad 1.0 \mathrm{mmol} \quad \mathrm{Cu}(\mathrm{NO} 3) 2.3 \mathrm{H} 2 \mathrm{O}$, $1.8 \mathrm{mmolZn}(\mathrm{CH} 3 \mathrm{COO}) 2.2 \mathrm{H} 2 \mathrm{O}, 1.0 \mathrm{mmol} \mathrm{SnCl} 2 \mathrm{In}$ the microwave. The reaction time is $10 \mathrm{~min}$. After the reaction is over, take it out and let it cool naturally in the air.

Vulcanization treatment: Put the sample and sulfur powder into the high temperature zone and low temperature zone respectively. First use a vacuum pump to extract the air in the quartz tube, then pass in argon, and then vacuum, and a certain amount of argon will be passed into the exhaust air, control the air pressure in the quartz tube to a fixed value, and then close the valves at both ends.

Selenization treatment: Put the prefabricated film and selenium particles after spin coating drying into a small single-port quartz tube, and then put the single-port quartz tube into a single-temperature zone vacuum annealing furnace. The air is removed by a vacuum pump, and then argon is introduced to complete the selenization process.

\subsection{Performance Test of Coating}

CZTS decomposes in the annealing process without sulfur atmosphere, and the decomposition process is shown in formula 1 :

$\mathrm{Cu}_{2} \mathrm{ZnSnS4}(s) \rightarrow \mathrm{Cu}_{2} S(s)+\mathrm{ZnS}(s)+\operatorname{SnS}(s)+\frac{1}{2} S_{2}(g)$

First, it decomposes to produce binary sulfides, and then due to the low melting point of SnS, it is easy to volatilize, and finally the reaction equilibrium proceeds to the right.

The absorption rate $a$ is defined by the corresponding integrating sphere total reflection data through the analysis software of the test instrument as shown in formula 2 :

$$
a_{s}=\frac{\int_{0.3}^{2.5}\left[1-p_{s}(\lambda)\right] \cdot E_{s}(\lambda) d \lambda}{\int_{0.3}^{2.5} E_{s}(\lambda) d \lambda}
$$

In the formula: $p \lambda$ is the monochromatic reflectance; $E \lambda$ is the spectral radiant density of the sun.

\section{INVESTIGATION AND ANALYSIS OF USING NEW COATING TECHNOLOGY TO IMPROVE THE PHOTOVOLTAIC PERFORMANCE OF SOLAR CELLS}

\subsection{The Effect of Vulcanization Process on the Performance of $\mathrm{Cu}_{2} \mathrm{ZnSnS}_{4}$ Film and Its Solar Cell}

The specific parameters of CZTS solar cells prepared under different vulcanization times are shown in Table 1. It can be seen from the test results that when the vulcanization time is $10 \mathrm{~min}$, the short circuit current density JSC and open circuit voltage VOC of the prepared CZTS solar cell are low, respectively $4.2 \mathrm{~mA} / \mathrm{cm} 2$ and $208 \mathrm{mV}$, and the final cell conversion efficiency is about $0.45 \%$. The lower JSC and VOC may be due to the shorter vulcanization time, the crystal grains of the prepared CZTS film are not fully grown, and are relatively small, making the grain boundaries more, increasing the defect state concentration, and thus increasing the carrier recombination. When the vulcanization time is too long for 40 minutes, the VOC and JSC of the prepared CZTS solar cell begin to decrease again, which is caused by the presence of $\mathrm{Cu} 2-\mathrm{xS}$ in the film, as shown in Figure 1. Based on the above results, when the vulcanization time is $40 \mathrm{~min}$, the performance of the prepared CZTS film is the best.

Table 1. Specific performance parameters of czts solar cells prepared under different vulcanization time

\begin{tabular}{|c|c|c|c|}
\hline$T(\mathrm{~min})$ & $V_{O C}(\mathrm{mV})$ & $J S C\left(\mathrm{~mA} / \mathrm{cm}^{2}\right)$ & Eff. (\%) \\
\hline 10 & 208 & 4.2 & 0.45 \\
\hline 20 & 312 & 5.8 & 0.51 \\
\hline 30 & 422 & 6.2 & 0.64 \\
\hline 40 & 325 & 5.9 & 0.54 \\
\hline
\end{tabular}




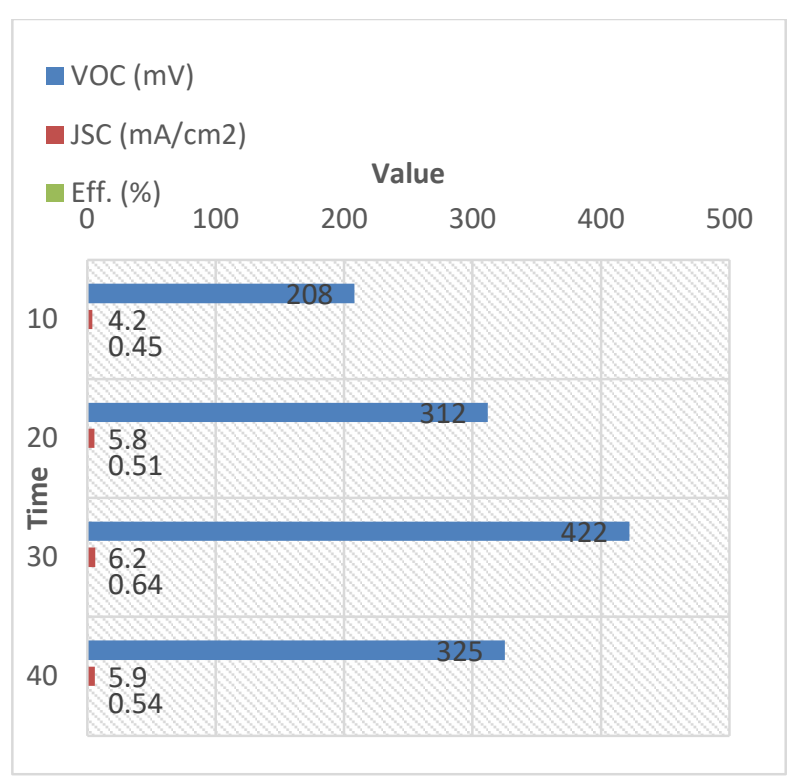

Figure 1. Specific performance parameters of CZTS solar cells prepared under different vulcanization times

When the vulcanization temperature is $400^{\circ} \mathrm{C}$ and the vulcanization time is $30 \mathrm{~min}$, the prepared CZTS film has better photoelectric properties. Therefore, we fixed the vulcanization temperature at $400^{\circ} \mathrm{C}$ and the vulcanization time at $30 \mathrm{~min}$ to study the effect of vulcanization pressure (100mbar, 200mbar, 300mbar and $400 \mathrm{mbar}$ ) on the performance of the prepared CZTS film. The prepared film is a kesterite structure CZTS with good crystallinity, and has obvious crystal plane preferred orientation. With the change of vulcanization pressure, no impurity phase was found. However, through EDS analysis, the pressure change of vulcanization has a certain effect on the ratio of elements in the film. With the decrease of vulcanization pressure, the content of $\mathrm{Sn}$ in the prepared CZTS film gradually decreases, and the other elements are basically unchanged. The vulcanization experiment in this paper is carried out under low pressure. The continuous decrease of vulcanization pressure increases the volatilization of $\mathrm{SnS}$, which leads to the decrease of $\mathrm{Sn}$ content in the film.

\subsection{The Effect of Selenization Process on the Performance of $\mathrm{Cu}_{2} \mathrm{ZnSnS} \mathrm{S}_{4}$ Film and Its Solar Cell}

Due to the influence of $\mathrm{Cu} 2-\mathrm{xSe}$ impurity phase and surface pores, the conversion efficiency of CZTSSe solar cells with selenization temperatures of $500^{\circ} \mathrm{C}$, $550^{\circ} \mathrm{C}$ and $600^{\circ} \mathrm{C}$ is obviously low. Especially when the selenization temperature is $600{ }^{\circ} \mathrm{C}$, due to the volatilization of $\mathrm{Sn}$ element, the $\mathrm{Cu} 2-\mathrm{xSe}$ heterophase exists on the surface of the prepared film, which makes the JSC and VOC of the film significantly decrease, and the final battery conversion efficiency is only $0.46 \%$. Generally speaking, as the selenization temperature increases, JSC increases, and VOC first increases and then decreases. Because the thin film prepared by selenization at $500^{\circ} \mathrm{C}$ has better compactness and the $\mathrm{Cu} 2-\mathrm{xSe}$ heterophase is relatively low, the highest efficiency of the prepared battery is $3.23 \%$, the open circuit voltage VOC is $284 \mathrm{mV}$, and the short circuit current density JSC is $26.4 \mathrm{~mA} / \mathrm{cm} 2$ is shown in Figure 2. Through the selenization treatment, the maximum JSC of the solar cell can reach $29.6 \mathrm{~mA} / \mathrm{cm} 2$, and the maximum VOC is only $312.1 \mathrm{mV}$, which is still far behind the open circuit voltage VOC of the current high-efficiency CZTSSe solar cells. The reason for the lower VOC may be that the interface compound of the battery is more serious. The reverse saturation current of the CZTSSe solar cell prepared at the selenization temperature of $550^{\circ} \mathrm{C}$ and $600^{\circ} \mathrm{C}$ is very large. Therefore, the CZTSSe thin-film solar cells prepared at $550^{\circ} \mathrm{C}$ and $600^{\circ} \mathrm{C}$ have lower VOC and FF.

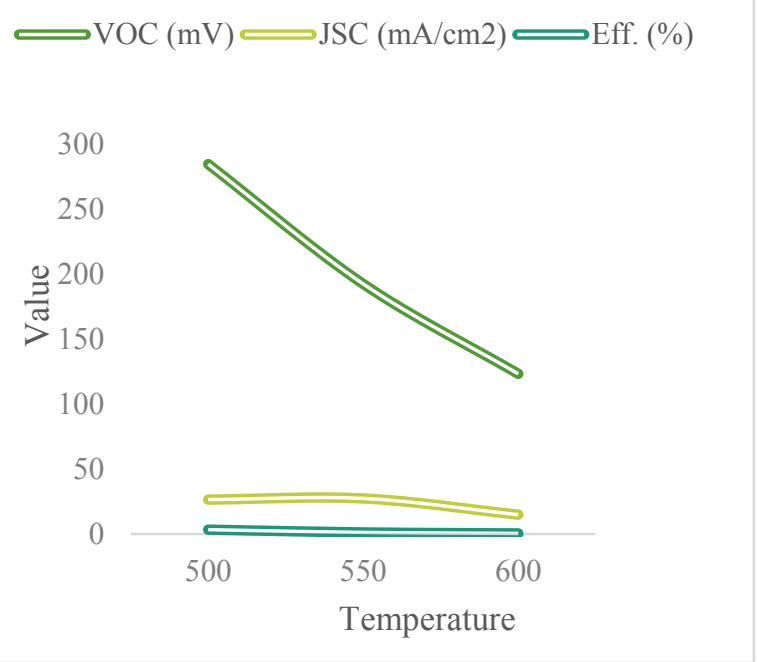

Figure 2. Specific parameters of the performance of CZTSSe solar cells prepared at different selenization temperatures

Compared with CZTSSe thin-film solar cells prepared by slow heating, the open-circuit voltage and short-circuit current density of thin-film solar cells prepared by rapid heating are significantly improved, with VOC reaching $321.2 \mathrm{mV}$ and JSC reaching $25.12 \mathrm{~mA} / \mathrm{cm} 2$. The cell conversion efficiency reaches $3.5 \%$, which is significantly improved compared with thin-film solar cells prepared by slow heating. However, the fill factor of the prepared battery has decreased. The rapid heating has caused the Mo electrode to deform greatly. There are obviously some microcracks in the Mo electrode. By optimizing the selenization temperature, time and heating rate, we finally get when the heating rate is $62^{\circ} \mathrm{C} / \mathrm{min}$ and the selenization temperature is $550^{\circ} \mathrm{C}$, The photoelectric performance of the CZTSSe thin film prepared when the selenization is $30 \mathrm{~min}$ is the best. 


\section{CONCLUSIONS}

The development of renewable energy has become a hotspot in energy research, so how to efficiently use solar energy has become a research topic for many researchers. In order to improve the efficiency of solar cells, this article selects the coating process for photovoltaic performance, and uses $\mathrm{Cu} 2 \mathrm{ZnSnS} 4$ thin film as the research object. Explore the effect of vulcanization process on the performance of $\mathrm{Cu} 2 \mathrm{ZnSnS} 4$ film and its solar cell and the effect of selenization process on the performance of $\mathrm{Cu} 2 \mathrm{ZnSnS} 4$ film and its solar cell. The theoretical simulation of the coating in this paper, as well as the cooperation of the experimental methods, make the solar selective coating process have theoretical support.

\section{REFERENCES}

[1] Shen G, Du Z, Pan Z, et al. Solar Paint from TiO2 Particles Supported Quantum Dots for Photoanodes in Quantum Dot-Sensitized Solar Cells[J]. Acs Omega, 2018, 3(1):1102-1109.

[2] Service R F . Cool paint job fights solar warmth[J]. Science, 2018, 361(6409):1303-1303.

[3] Miller J , Nwe K, Youn Y, et al. Development of a low environmental impact, porous solar absorber coating utilizing binary/ternary solvent blends for CSP systems[J]. The Korean journal of chemical engineering, 2019, 36(6):996-1003.

[4] N Martínez, Rico A, CJ Múnez, et al. Improving durability of silicone-based paint coatings used in solar power plants by controlling consolidation procedures[J]. Solar Energy, 2020, 199(31):585-595.

[5] FG Aránzazu, Adel J , Florian S , et al. Solar Reflector Materials Degradation Due to the Sand Deposited on the Backside Protective Paints[J]. Energies, 2018, 11(4):808.

[6] Souto T , Almeida M , Leal V, et al. Total Solar Reflectance Optimization of the External Paint Coat in Residential Buildings Located in Mediterranean Climates[J]. Energies, 2020, 13(11):2729.

[7] Al-Hamadani A, Al-Azawi L . The Effect of Different Paint Material of Absorber on Exergy and Energy of Parabolic Solar Dish[J]. International Journal of Science and Research (IJSR), 2018, Volume 8(Issue 11, November 2019):794-801.

[8] Pakala M , Kumar G A , Koka M . Design, fabrication and testing of solar concrete collector at Kakinada[J]. Invertis Journal of Renewable Energy, 2018, 8(1):10.
[9] Mehmood R, Tabassum R, Kuharat S , et al. Thermal Slip in Oblique Radiative Nano-polymer Gel Transport with Temperature-Dependent Viscosity: Solar Collector Nanomaterial Coating Manufacturing Simulation[J]. Arabian Journal for Science and Engineering. Section A, Sciences, 2019, 44(2):1525-1541.

[10] Mico-Vicent B , Lopez-Herraiz M ， Bello A, et al. Synthesis of pillared clays from metallic salts as pigments for thermosolar absorptive coatings[J]. Solar Energy, 2017, 155(oct.):314-322.

[11] Park D , Kim M, So W, et al. Evaluation of Bifacial Si Solar Module with Different Albedo Conditions[J]. Current Photovoltaic Research, 2018, 6(2):62-67.

[12] Lei S L , Liang G J , Wang Y, et al. Sol-gel combustion synthesis and characterization of $\mathrm{CoCr} 2 \mathrm{O} 4$ ceramic powder used as color solar absorber pigment[J]. Optoelectronics Letters, 2020, 16(5):365-368. 